\title{
ВОЗМОЖНОСТИ ГЕОФИЗИЧЕСКИХ МЕТОДОВ ДЛЯ ПРОГНОЗИРОВАНИЯ ТРЕЩИНОВАТОСТИ КОЛЛЕКТОРОВ
}

\author{
Орехов Александр Николаевич',
}

orekhovan@mail.tomsknet.ru

\author{
Амани Мангуа Марк M', \\ mangouam@yahoo.fr
Национальный исследовательский Томский политехнический университет, Россия, 635050, г. Томск, пр. Ленина, 30.

Приводятся результаты анализа российских и зарубежных публикаций, выполненного с целью характеристики современного состояния вопроса применения геофизических методов для прогнозирования трещиноватости коллекторов. Дано описание особенностей возникновения трещиноватости в зависимости от её генезиса. Описаны тектонические и геологические условия трещинообразования. Приведена геологическая модель образования трещин. Показана связь между трещинами и разломами. Охарактеризованы методы, позволяющие изучить трещиноватость как в Скважине (методы геофизических исследований скважин), так и с поверхности (по результатам сейсморазведочных работ). Указаны наиболее востребованных для решения этих задач сейсмические атрибуты. Приведена характеристика используемых методов ГИС и определён круг решаемых задач как для наиболее широко распространённых вариантов геофизических исследований скважин, так и для инновационных методов, предлагаемых компанией «Шлюмберже». Сделан вывод о необходимости комплексирования методов ГИС. Описаны физические основы сейсмических методов изучения трещиноватости и основные атрибуты. Отмечены их возможности и ограничения. И на этой основе очерчен круг вопросов, требующих дополнительного изучения.

Целью исследования является определение направлений дальнейших исследований для повышения эффективности геофизических работ при изучении трещинных коллекторов путём создания обзора геофизических методов, применяемых для выделения зон повышения трещин, последующего анализа существующих методик и определения оптимальных путей решения этих задач. Результаты. Проанализированы геофизические методы выявления трещиноватых коллекторов (как методы ГИС, так и сейсмические атрибуты). Определён круг нерешённых задач. Намечено направление дальнейших исследований.

\section{Ключевые слова:}

Коллектор, трещинно-кавернозные тип, сейсмические атрибуты, геофизические методы исследования скважин.

\section{Введение}

В нефтепромысловой отрасли специалисты по геологии разрабатывают технологию изучения объекта исходя из характеристик пластов. Одно из наиболее широко используемых определений предложено Т. Ван Голф-Рахтом. По его мнению, под «геолого-геофизической характеристикой пласта, понилается совокупность исходной инфорлации о породах, слагающих пласт и насьщающих их флюидали» [1]. Для того чтобы изучать трещиноватость коллекторов, необходимо знать условия формирования и физические характеристики исследуемых резервуаров. Соответственно, для формирования оптимального комплекса геофизических методов, используемых для прогноза трещинно-кавернозных коллекторов, нужно учитывать параметры и условия их трещинообразования.

Трещиноватость горных пород - один из самых важных геологических параметров трещиноватых коллекторов. Она определяет пространство (т. н. вторичная пористость для коллекторов) [2]. Так как трещинные коллекторы отличаются от обычных поровых коллекторов, необходимо учитывать их особенности. Для лучшего понимания сути вопроса кратко охарактеризуем современные представления о теории трещинообразования и на её основе обоснуем характерные черты трещинных коллекторов и возможности геофизических методов для выделения таких коллекторов.

Трещина, при сегодняшнем состоянии изученности вопроса, определяется как некая поверхность, сопряжённая с нарушением сплошности или потери сцепления материала (горной породы) [1]. Таким образом, разрывом называется процесс по потере сцепления горной породы. Результатом этого процесса и является возникновение трещины как таковой [1, 3-5]. В зависимости от наличия или отсутствия смещения пород по образовавшейся трещине она может представлять собой либо разлом (нарушение) - в случае определяемых смещений пород вне зависимости от их направления, либо просто трещину (макротрещину) - если смещение не установлено [1]. Соответственно можно говорить о том, что причиной возникновения трещин является нарушение сплошности пласта. При этом возникают различные блоки, разделённые трещинами, сплошность пород нарушается. Однако какие-либо смещения этих блоков не определяются.

Происхождение трещин. При изучении осадочных пород применение вышеприведённого определения разрыва может оказаться проблематичным $[3,6,7]$. Причину этого следует искать в тесной связи геологической обстановки и степени трещиноватости пород. 
Тектонические условия. Одним из наиболее существенных вопросов, которые требуют исследования при решении вопросов происхождения трещин, а также при характеристике их связи со структурными и тектоническими условиями, является вопрос оценки интенсивности распространения трещин. Не менее значимой представляется и задача определения степени влияния трещин на формирование ловушек углеводородов.

По мнению М. Фридмана и Д. Стирнса [5, 8] основными типами трещин являются:

- трещины, возникшие в процессе складкообразования (генетически с ним связанные);

- региональные трещины, образование которых, как правило, связано с формированием локальных структур.

С ними не вполне согласен Дж. Хадсон [1, 9]. Он проводил исследования на территории Аризоны и Юты. Полученные результаты показали, что, скорее всего, плоскости сочленения в пластах и трещины образовывались на ранних этапах седиментогенеза. А основной причиной их возникновения являлись усталостные деформации, обусловленные приливно-отливными напряжениями.

Изучая осадки Сиднейского бассейна, А. Кук [10] выяснил, что разрозненные трещины, сформировавшиеся в процессе седиментогенеза, могут иметь весьма длительный период существования, сохраняясь, в том числе, и на этапах захоронения и консолидации осадков. Этот вывод ставит под сомнение ранее высказанное суждение С. Прайса $[1,9]$ о малой вероятности существования в молодых осадках долгоживущих разрозненных трещин. По его мнению, в ходе процесса уплотнения осадков, а особенно их последующего диагенеза, ранее образовавшиеся трещины должны залечиваться.

Результаты полевых наблюдений позволили П. Харрису предложить свой вариант типизации трещин. Он считает, что существует два основных типа трещин:

«а) трещины, которые связаны с геометрией структуры коллектора. Они имеют постоянную ориентацию и упорядоченную систему распространения на всей площади наблюдений. Данная связь трещин со структурой является особенностью локальных участков доскладчатого периода;

б) трещины, которые не связаны с геометрией структуры коллектора. Это трещины, включающие неправильные или изогнутые разрывы при отсутствии какой-либо закономерности в их ориентации. Такие трещины связаны с различными поверхностными явлениями (оползнями, оседанием пластов под действием силы тяжести и т. д.)» [1].

Геологические условия трещинообразования. Как правило, трещинные коллекторы типичны для хрупких пород, характеризующихся пониженной пористостью и залегающих в сейсмически активных регионах с повышенной частотой проявления тектонических процессов $[11,12]$. Возни- кающие в этих условиях трещины имеют сравнительно большие геометрические размеры, причём как по ширине, так и по протяжённости, и их часто называют макротрещинами.

Если же для исходной породы характерны несколько повышенные пластичность и пористость (речь в данном случае идёт о межгранулярной пористости), трещины имеют небольшие геометрические размеры. «Раскрытость» таких трещин тоже ниже. По своему генезису они являются трещинами разрыва. А по размерам - микротрещинами.

Кроме того, имеют место случаи, когда трещины возникают не как следствие разнонаправленных тектонических напряжений, а в результате уменьшения сцепления частиц породы. Такую реакцию породы может вызывать целый ряд причин, а именно:

- остывание эффузивных (и интрузивных) пород всегда сопровождается уменьшением их объёма; - процесс складкообразования, за счёт увеличенных напряжений в замковых частях складок, приводит к ослаблению сцепления зёрен пород на этих участках;

- высыхание пород, содержащих глинистые минералы, приводит к их (пород) растрескиванию вследствие уменьшения объёма за счёт потери воды;

- процессы денудации, в ходе которых, за счёт эрозии мощность перекрывающих отложений становится различной в разных частях среды. Это приводит к формированию различных напряжений по ослабленным зонам.

Геологическая модель трещинообразования. Известно несколько моделей формирования трещин. Охарактеризуем основные.

Базовой моделью образования трещин является модель Киблье [12]. Она предполагает расчёт карт равной вероятности развития трещин и выявление на основе их анализа участков наибольшей вероятности трещинообразования. Суть этой модели состоит в следующем. Предполагается, что по результатам седиментогенеза были сформированы плоские слои осадочных горных пород, примерно повторяющие форму нижележащих отложений. Далее к ним были приложены тектонические напряжения (в ходе процессов складкообразования) и горное давление (как результат гравитационного воздействия вышележащих отложений). Это суммарное воздействие и привело, в конечном итоге, к возникновению сети трещин. Таким образом, если мы проанализируем современную форму пластов и рассчитаем критический модуль упругости в каждой точке среды, мы получим возможность оценить вероятность возникновения трещин при предполагаемых смещениях. При этом надо иметь в виду, что вероятность трещинообразования повышается при уменьшении критического модуля упругости.

Л. Рамстад $[1,12]$ развил идею Киблье. При этом он показал, что использованный ранее метод моделирования являлся не совсем удачным и пред- 
ложил использовать метод конечных элементов. Ключевым условием его применимости является соблюдение закона линейности для горных пород, которые (в первом приближении и в зависимости от состава) можно отождествлять с упругими и упруго-вязко-пластичными материалами.

\section{Связь между трещинами и разломами}

Тектонические трещины в горных породах встречаются значительно чаще разломов. Причиной их возникновения являются главным образом напряжения, появляющиеся на этапах тектоногенеза. Они, с одной стороны, могут быть связаны с различными локальными тектоническими структурами, такими как разломы, складки, а с другой - возникать в ходе напряжений, связанных, например, с движением литосферных плит. Таким образом, можно говорить о том, что природа тектонических трещин разнообразна и их возникновение может быть обусловлено различными источниками напряжений, что приводит $к$ формированию трещин различных масштабов. Большинство исследователей в настоящее время выделяют три основные последовательные стадии деформации, приводящие к появлению тектонических трещин, как это показано на рис. $1[6-8,13]$.

1. Стадия упругой дефорлации. Деформации этой стадии не приводят к разрушениям пород. При снятии нагрузки порода восстанавливает изначальные геометрические характеристики. Таким образом, можно говорить о том, что деформации этой стадии являются обратимыми.

2. Стадия пластической дефорлации. В случае превышения тектоническими напряжениями порога обратимости (предела упругости) порода безвозвратно изменит свои геометрические характеристики. Деформации этой стадии приводят к образованию складок, но не приводят к нарушению сплошности пород. Необходимым условием формирования деформаций этой стадии является не превышение тектоническими напряжениями предела прочности пород.

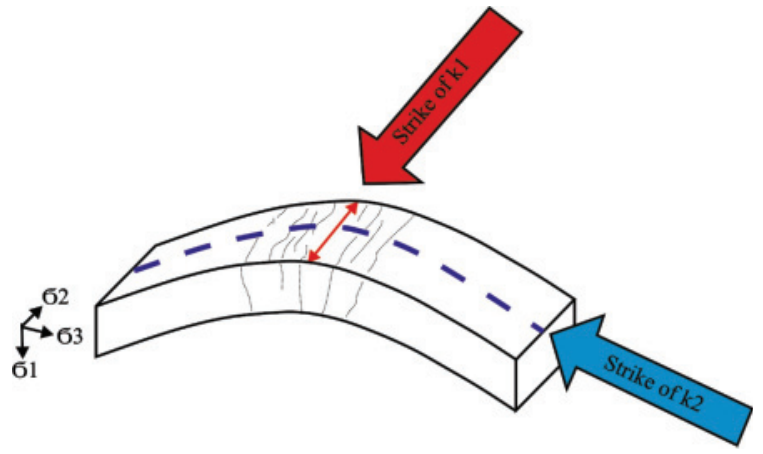

Рис.1. Пример ориентации напряжения с направлением тре щин [14]

Fig. 1. Example of stress orientation with fracture direction [14]

3. Стадия хрупкой или разрывной дефорлации. Как правило, это заключительная стадия де- формации пород под действием тектонических сил. Деформации этой стадии возникают тогда, когда порода ведёт себя как хрупкое тело. То есть когда тектонические напряжения существенно превышают все пределы сопротивляемости породы. Это приводит к появлению т. н. «хрупких» деформаций, связанных с потерей сплошности и формированием различных тектонических трещин.

\section{Обнаружение зон повышенной трещиноватости}

Прямая оценка трещиноватости. Исследования керна - это наиболее достоверный метод в изучении трещиноватости коллекторов. Но при бурении горные породы деформируются, происходит разгрузка напряженных состояний, вследствие чего образуются новые (техногенные) трещины и изменяется апертура ранее существовавших трещин. Кроме того, радиус исследований у подобных методов незначительно превышает радиус скважины.

Скважинные методы.

К ним относятся:

Гидродинамические исследования скважин, которые позволяют оценить расстояние от скважин до зон повышения трещиноватости. Гидропрослушивание скважин и трассерные исследования позволяют выделить преимущественные направления фильтрации. Также можно изучать трещиноватость на обнажениях, где имеется возможность наблюдать распространение трещин и их взаимодействие на значительной площади. Необходимо иметь в виду, что только вышеописанных исследований недостаточно для достоверного определения распределения сети трещин в породеколлекторе.

Применение методов геофизических исследований скважин. Попытки найти способ прямого выделения трещиноватости, а также оценки пространственной плотности трещиноватости предпринимались уже давно. Со второй половины прошлого века для решения этих задач активно пытались использовать данные ГИС $[15,16]$. Однако однозначного решения этой проблемы не получено до сих пор. В основном это обусловлено сложностями выделения трещин. Так, например, оказалось, что задача описания системы трещин в стволе скважин весьма сложна и это нельзя сделать однозначно верно. В силу этих причин решение проблемы, как это обычно принято в геофизике, стали искать в комплексировании методов каротажа.

Дадим краткую характеристику наиболее востребованных при изучении трещиноватости методов ГИС.

Метод салопроизвольной поляризации (СП). Измеряемым параметром в этом методе является разность потенциалов между неподвижным электродом, расположенным на поверхности, и подвижным электродом, перемещаемым по стволу скважины. Если в скважине встречаются проницаемые породы, то значение СП меняется и отклоняется от уровня фона (линии глин). Причём это яв- 
ление возникает в случае наличия и пористых, и и трещиноватых пород. Определение природы аномалий - пористость или трещиноватость - возможно исходя из анализа геологических характеристик разреза $[17,18]$.

Причиной возникновения отрицательных аномалий СП является повышение степени фильтруемости бурового раствора. Таким образом, можно говорить, что для случая развития трещиноватости эти аномалии имеют фильтрационную природу. Однако, в силу того, что такие же аномалии возникают и за счёт окислительно-восстановительных процессов при наличии в породе и в трещинах пирита и др., этот факт, а также то, что в карбонатах данный метод не работает, заставляет с осторожностью относиться к результатам выделения трещин с его помощью, заставляет использовать его только в комплексе.

Галла-летод. Уровень естественной радиоактивности сам по себе никак не связан со степенью трещиноватости пород. Однако он однозначно связан с количеством глины (как хорошего сорбента ЕРЭ) в среде. Также на уровень концентрации ЕРЭ в среде влияет и количество сорбированных на скелете горной породы радиоактивных минералов, попавших туда в силу фильтрации воды по трещинам $[18,19]$. Поэтому при определённых условиях повышение естественной радиоактивности по данным гамма каротажа может служить достоверным признаком наличия повышенной трещиноватости.

Кавернометрия. Применение этого метода ГИС для прогноза трещиноватости основывается на том, что в силу более высокого давления бурового раствора (по сравнению с пластовым давлением) в зонах повышенной трещиноватости происходит ускоренное формирование глинистой корки, за счёт «задавливания» бурового раствора в горную породу. В этом случае по результатам кавернометрии фиксируется уменьшение диаметра скважины. Естественно, что данная методика работает только при бурении на глинистых растворах либо на растворах со специальными добавками.

Терлометрия. Применение этого метода ГИС для определения степени трещиноватости основано на том, что существует разница между температурой бурового раствора (как правило, он холоднее) и горной среды $[15,16]$. При циркуляции раствора в скважине наиболее значимо температура будет понижаться напротив проницаемой (трещиноватой) части разреза, которая, таким образом, может быть зафиксирована чувствительными скважинными термометрами, обладающими низкой тепловой инерцией и хорошей чувствительностью.

Наклонолетрия. Принцип использования этого метода для определения трещиноватости основан на том факте, что проницаемая зона характеризуется несколько повышенной проводимостью $[15,16]$. При измерении сопротивления в процессе вращения зонда на каждом из четырёх башмаков при благоприятных условиях можно зафиксиро- вать разнонаправленные трещины, которые должны проявиться, как было отмечено выше, понижение сопротивления, по сравнению со сплошной средой.

Методы ГИС для определения пустотности. Как правило, в эту группу включаются акустический, нейтронный и плотностной каротаж, которые позволяют, с одной стороны, оценивать трещиноватость, а с другой, при благоприятных условиях, фиксировать наличие вторичной пустотности (акустический каротаж) [16, 19].

Акустический метод. Физической основой его применения для оценки трещиноватости и вторичной пустотности является наличие теоретической связи между их наличием и особенностями распространения в среде упругих волн. Несмотря на очевидную связь между этими параметрами, полученные практические результаты в настоящее время не столь однозначны. Однако большинство специалистов $[20,21]$ считает именно этот метод наиболее перспективным для применения в дальнейшем в качестве основного метода ГИС для регистрации трещиноватости.

К его основным достоинствам можно отнести возможность уверенного разделения пород по их акустическим свойствам и сравнительно невысокую чувствительность к неоднородностям ствола скважины.

Плотностной метод. Физической основой применения плотностного метода для определения трещиноватости служит очевидная связь между трещиноватостью (пористостью) и плотностью $[15,19]$. Чем выше трещиноватость, тем ниже плотность, что проявляется в увеличении скорости счёта. Основные ограничения в применении этого метода ГИС связаны с тем, что зонд не ориентирован и не вращается. В силу этих ограничений, может оказаться, что трещиноватость будет установлена только с одной стороны ствола скважины.

K преимуществам плотностного метода [18] можно отнести возможность количественного определения величины пустотности.

Нейтронные методы. Нейтронный каротаж, так же как и плотностной, позволяет измерять общую пустотность $[15-17,19]$. Для него характерны те же недостатки и ограничения, что и для плотностного каротажа. Однако, в отличие от последнего, нейтронные методы (за счёт фиксации повышенного содержания водорода в породе) позволяют более уверенно фиксировать открытые трещины.

Скважинный телевизор. При использовании скважинного акустического телевизора (CAT) оператор получает акустическую развёртку ствола скважины, где трещинам, кавернам, пустотам и другим нарушениям сплошности пород в явном виде соответствуют участки изменения интенсивности волновой картины. Метод характеризуется весьма высокой разрешающей способностью и в ряде случаев может помочь отказаться от непрерывного отбора керна. 
Считается, что этот метод является единственным прямым методом изучения трещиноватости в открытом стволе. Также необходимо отметить, что достоверность получаемых при использовании САТ результатов можно повысить при использовании керновых данных.

Отдельно надо остановиться на современных методах выделения трещин, предлагаемых компанией «Шлюмберже».

Sonic Scanner: 3D акустическое зондирование [22]. Широкий частотный спектр излучателей, используемых в платформе Sonic Scanner, позволяет регистрировать волновые поля с высоким отношением сигнал/шум независимо от интервального времени распространения волн в породе, что устраняет необходимость многократных рейсов. Увеличенная, по сравнению с обычными акустическими приборами, антенна приемников, которая состоит из 13 станций по 8 азимутальных приемников в каждой, и большой диапазон расстояний между монопольными излучателями и приемниками позволяют получать радиальный профиль изменения интервального времени распространения продольной волны по мере удаления от стенки скважины вглубь пласта. Аналогичный профиль для поперечной волны получают благодаря зависимости глубинности измерения изгибной волны от частоты сигнала посредством инверсии ее дисперсионной кривой. Получаемые полевые данные позволяют провести классификацию анизотропии пласта, определить её тип и характер.

FMI (азилутальный электрический ликроимиджер). Ещё одной методикой, предложенной компанией «Шлюмберже» для изучения трещиноватости в стволе скважины, является использование азимутального электрического микроимиджеpa [23]. Он обладает достаточно высоким разрешением (не более 5 мм по вертикали и горизонтали) и позволяет работать в заполненных буровым раствором на водной основе скважинах, что делает его чрезвычайно полезным. Однако в случае использования полимерных растворов эффективность этого метода существенно снижается.

Quanta Geо (азимутальный электролагнитный микроилиджер ) [24]. Эта аппаратура используется для проведения структурного анализа, оценки естественной и техногенной трещиноватости пород, оценки вторичной пористости кавернопоровых карбонатных коллекторов, уточнения эффективной мощности коллекторов в условиях тонкого переслаивания песчано-глинистых отложений, оценки азимута максимального горизонтального напряжения, проведения седиментологического анализа, высокоточной привязки керна по глубине (точность составляет 3-5 cм), азимутального ориентирования керна. В зависимости от геолого-технологических условий измерений применяются электрические, электромагнитные или ультразвуковые пластовые микроимиджеры.

ОВМI (Азилутальный электролагнитный микроилиджер) [25]. В геологической интерпрета- ции имиджи используются для определения внутрипластовой слоистости и текстурных особенностей породы, причем размер отдельно взятых элементов может не превышать 1 см (0,4 дюйма). Отмечены также наблюдения на имиджах открытых и залеченных трещин, размер которых менее 1 см.

UBI (ультразвуковой высокоразрешающий микроилиджер) [26] Он позволяет получать характеризующиеся высоким разрешением акустические изображения (имиджи) ствола скважины, заполненного буровым раствором на водной или нефтяной основе. Имиджи позволяют определять наклонные пласты, трещины и другие элементы залегания пластов, вскрытых скважиной. Точные измерения сечения ствола скважины позволяют сделать выводы о стабильности стенок скважины и овальности ствола.

Тел не ленее необходимо признать, что даже эти методики, взятые по отдельности, не дают возложности однозначного выделения трещин и оценки трешиноватости коллекторов в иелол.

Комплексирование методов ГИС. Как было отмечено выше, при изучении трещиноватости в стволе скважины мы сталкиваемся с проблемой, типичной для геофизики в целом, а именно - практически ни один метод ГИС (возможно за исключением (AT) не может картировать её в моноварианте. Соответственно, решение этой проблемы такое же, как и для других задач, стоящих перед геофизическими методами, а именно - комплексирование $[16,27]$. Таким образом, эффективность решения задач выделения трещин в стволе скважины напрямую зависит от качества формирования поискового комплекса ГИС.

Как показывают вышеприведённые результаты анализа современных способов определения трещиноватости, исследования в стволе скважины, они всё-таки позволяют с определённой долей уверенности (которая резко повышается в случае использования скважинного телевизора) выделять трещины и оценивать трещиноватость коллекторов. Однако этого нельзя сказать о способах оценки трещиноватости при проведении полевых геофизических (сейсморазведочных) работ. Необходимо иметь в виду, что возможность оценки трещиноватости на этом этапе позволит существенно повысить достоверность прогноза коллектора и, как следствие, эффективность геофизических работ в целом.

Обнаружение и зон повышенной трещиноватости. Сейсмические методы. Сейсмические исследования должны позволить значительно снизить неопределённость при оценке трещиноватости. Несравненный плюс таких исследований заключается в том, что современная трёхмерная (3D) сейсмическая съемка равномерно охватывает значительную площадь над месторождением, независимо от неравномерно расположенных на площади скважин [27, 28].

По сейсмическим материалам сложно сказать, сколько именно трещин находится в пласте и ка- 
кова пространственная ориентация каждой из них, но можно выделить зоны повышенной трещиноватости и попытаться определить их преимущественную азимутальную ориентировку.

\section{Физические основы для выделения трещин по сейсмическим данным}

Анализируя характеристики упругих волн в зонах трещиноватости, можно сделать вывод, что наиболее чувствительными являются динамические параметры продольной и поперечной волны [20], а именно - амплитуда, затухание и энергия (рис. 2). Весьма чувствительны к зонам трещиноватости (в связи с их высокой проницаемостью) являются параметры волн Стоунли-Лэмба. На приведённом рисунке хорошо видно, что области с изменёнными характеристиками (спектр и форма) акустического сигнала соответствуют зонам повышенной трещиноватости. Это же уверенно фиксируется и при анализе фазовой корреляции (а имен- но - в виде областей её нарушения, особенно в области поперечных волн) и волновой картине (падение амплитуд практически всех волн).

\section{Направления развития сейсморазведки}

при картировании зон повышенной трещиноватости

Азимутальный анализ амплитуд P- и S-волн. S. Crampin, V. Grechka, H.B. Lynn и другие [29-34] предлагают технологии азимутального анализа амплитуд (AVAZ), основанные на азимутальной анизотропии P- и S-волн, для изучения зон повышенной трещиноватости.

Анализ атрибутов волнового поля. Эта технология анализа сейсмических данных на сегодняшний день считается одной из наиболее перспективных, как отмечается в работах [2, 35-45]. Но при этом она же является и одной из наименее разработанных. Сейсмические атрибуты являются наиболее распространёнными и общедоступными, каждый из них подчёркивает определённую характе-

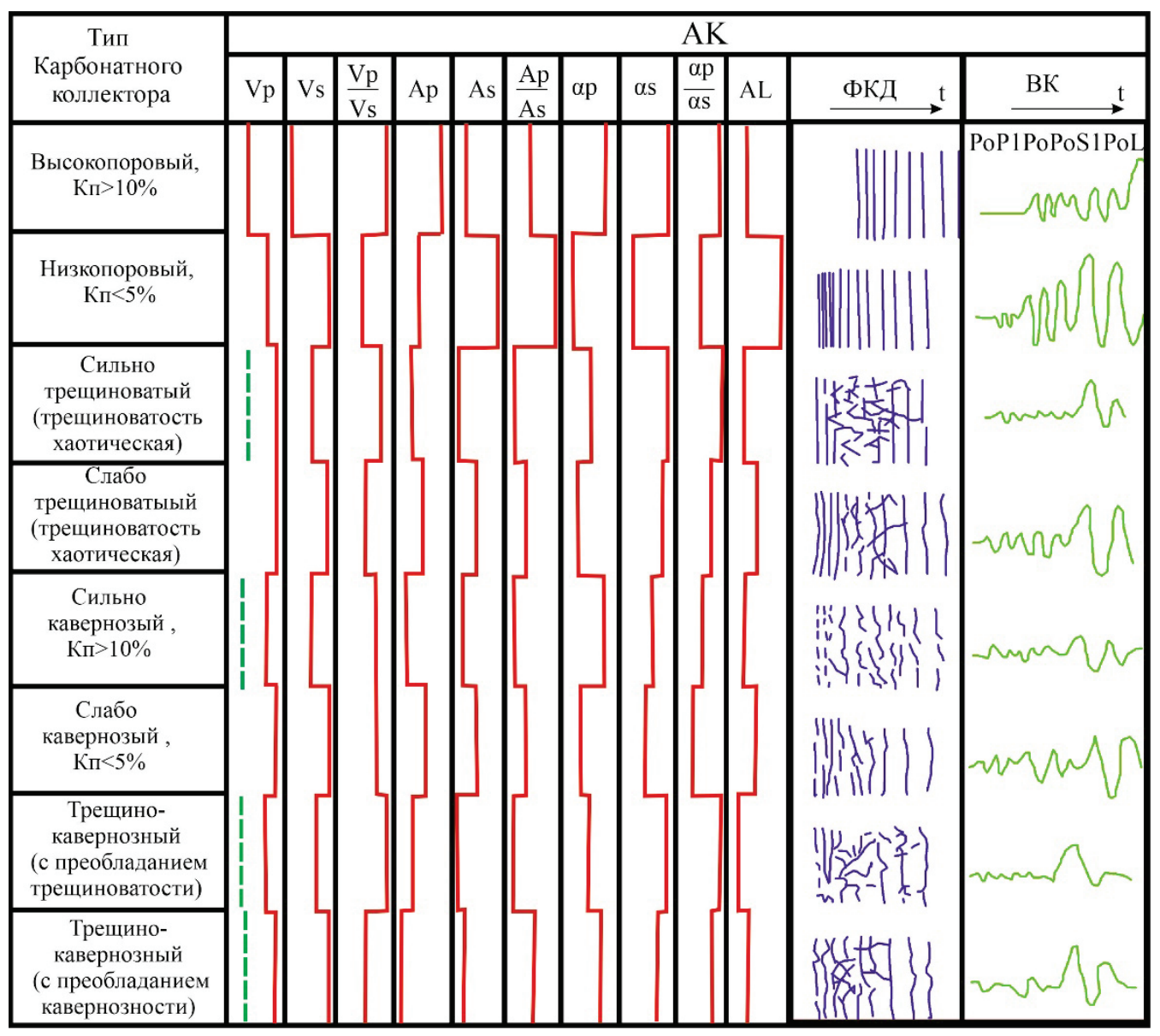

Pис. 2. Обобщенная схема изленения акустических параметров в разрезе, представленнол чередованиел пластов с различныл типол пустотного пространства [20]: Kn - коэффициент пористости; Vp - скорость продольной волны; Vs - cкорость поперечной волны; Ар - алплитуда продольной волны; As - алплитуда поперечной волны; $\alpha$ - коэффициент затухания продольной вол-

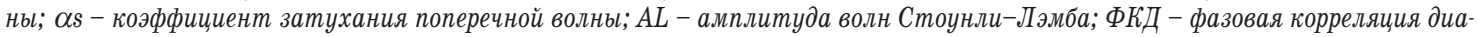
грамл; ВК-волновая картина

Fig. 2. Generalized scheme for changing acoustic parameters in a section represented by alternation of strata with different types of porosity [20]: Kn-coefficient of porosity; Vp - velocity of the longitudinal wave; Vs - transverse wave velocity; Ap - amplitude of the longitudinal wave; As - amplitude of the transverse wave; $\alpha$ - attenuation coefficient of the longitudinal wave; $\alpha$ - shear attenuation coefficient; $A L$ - amplitude of the Stoneley-Lamb waves; $\Phi$ KД - phase correlation of diagrams; BK-wave pattern 
ристику волнового поля, связанную с трещинами. На практике анализ сейсмических атрибутов широко применяется при поиске месторождений углеводородов, оценке структуры, определении соли, обнаружении структурных несогласий. Также он позволяет определить ориентацию структуры, может выступать как индикатор трещин. Дополнительно этот метод даёт возможность выделять русла, характеризовать текстуры, определять наличие карбонатов в разрезе, выступать в роли индикатора литологии и углеводородов, прогнозировать коллектор, его петрофизические свойства. Полученные данные могут быть использованы при моделировании резервуара. С методической точки зрения, результаты анализа атрибутов волнового поля могут быть использованы для умещения шума. Однако особую актуальность анализ сейсмических атрибутов приобретает в случаях локализации коллекторов в карбонатных и терригенных разрезах в ловушках основных типов. В условиях сложных коллекторов, трещиноватых в Западной Сибири, анализ сейсмических атрибутов играют важную роль в процессе картирования, выделения разломов и прогнозирования продуктивности коллекторов [46].

Наиболее распространёнными и общедоступными атрибутами для решения этой задачи (картировании зон повышенной трещиноватости) являются геометрические атрибуты, преимущественно направлены на анализ геометрии сейсмического горизонта, что является прямым признаком наличия трещиноватости. К геометрическим атрибутам относится большая часть всех применяющихся на практике методов. Наиболее информативные из них следующие:
Кривизна - является мерой структурной деформации, анализирует форму сейсмического горизонта и показывает, насколько он изогнут в некоторой точке. Атрибуты кривизны начали активно использоваться для предсказания малоамплитудных разрывных нарушений и зон трещиноватости с тех пор, как была продемонстрирована корреляция значений кривизны с разрывными нарушениями [47]. По мнению авторов работы $[14,47,48]$, кривизна - превосходная мера палеодеформаций, приводящих к растрескиванию пород. Данный атрибут позволяет не только картировать трещиноватые зоны, но и судить о плотности трещин. Связь кривизны с плотностью трещин базируется на следующих трех предположениях: порода хрупкая и поэтому подвержена трещинообразованию; рост кривизны предполагает рост напряжения; рост напряжения предполагает рост плотности трещин. Разработка основ вычисления кривизны по сейсмическим данным выполнена S.Chopra и K. Marfurt [48] и предполагает вычисление искомых параметров только вдоль отражающих горизонтов. Несмотря на ряд практических положительных примеров использования так называемой погоризонтной кривизны, она содержит ряд недостатков [14]. Многими авторами $[14,47]$ было показано, что различные меры кривизны (кривизна азилут, среднял кривизна, максилальная кривизна Ктах, минилальная кривизна Kmin, Гауссова кривизна и т. д.) имеют высокую корреляцию с разрывными нарушениями, но информативными для картирования тектонической нарушенности являются наибольшие положительная и отрицательная кривизны.

Когерентность (Дисперсия) позволяет выделить несоответствие сигнала по латерали и указы-

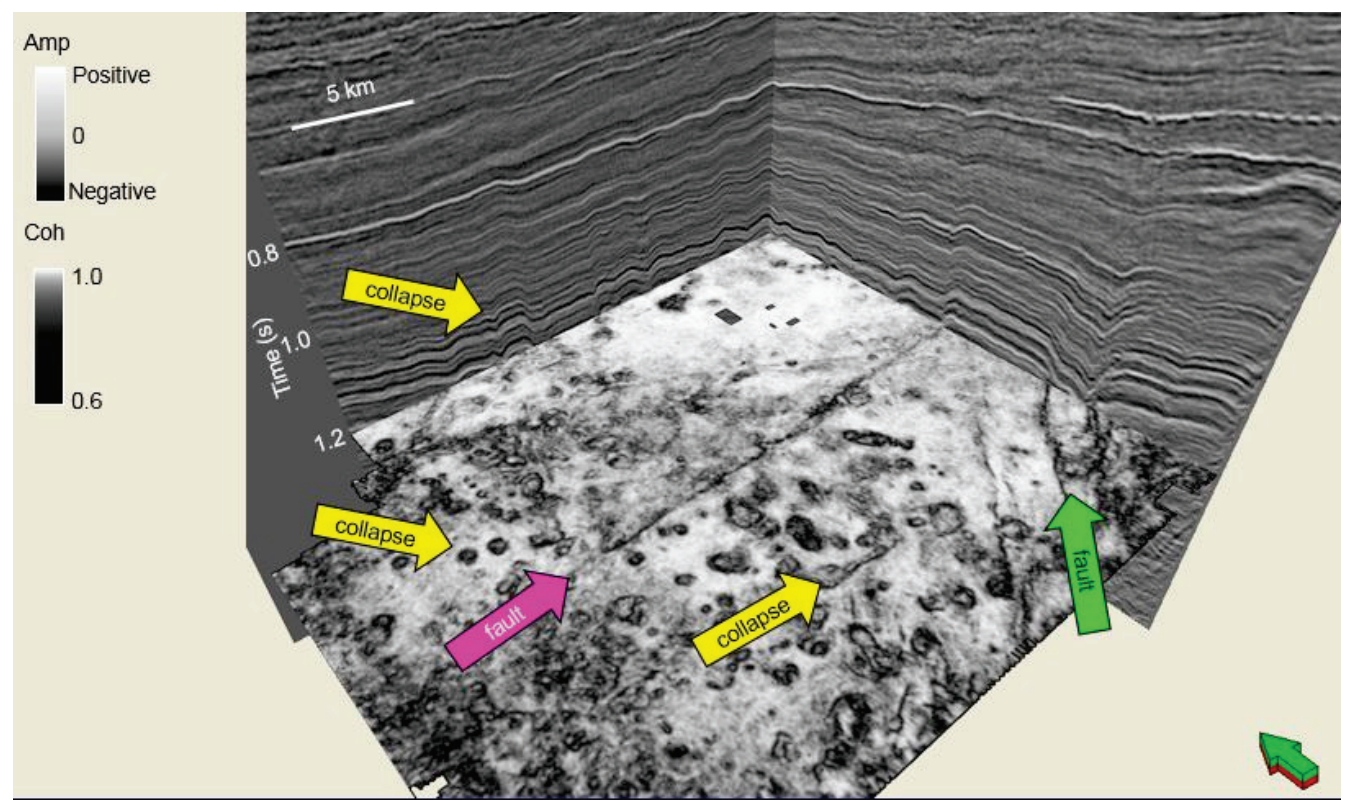

Рис.3. Пример использования среза куба когерентности времени при $t=1,2$ с на горизонте для выделения разломов и трещиноватых зон $[41,42]$

Fig. 3. Example of using slice of time coherence cube at $t=1,2 \mathrm{~s}$ on the horizon to isolate faults and fissured zones [41, 42] 
вает на неоднородности вследствие зон разломов, трещин и разрывных нарушений, как это показано на рис. 3. Коэффициент когерентности впервые введен в 1930 г. американским математиком Норбертом Винером. С тех пор концепция, положенная в основу этого атрибута, была успешно адаптирована для применения в различных областях знаний. По данным различных авторов [11, 40, 45, 49] этот атрибут успешно применяется в том или ином виде в сейсморазведке при выявлении и картировании перечисленных стратиграфических и структурных перерывов.

В первых работах по данному направлению $[14,47,48]$ был предложен способ расчёта т. н. «мгновенной» когерентности. Для этого использовался набор сейсмотрасс и единый отсчёт времени. Далее этот подход был усовершенствован [12] применительно к понятию аналитического сигнала (огибающей) сейсмической трассы. Для расчета мгновенной когерентности указанные авторы использовали сейсмограммы ОСТ (общей срединной точки), которые предварительно были исправлены путём введения статических и кинематических поправок, что давало возможность выравнивания сигнала.

По состоянию на сегодняшний день для расчётов используются уже т. н. «окончательные сейсмические изображения». Это дало возможность оптимизировать алгоритм расчётов таким образом, что стало возможным как существенное сокращение времени вычислений, так и получение более устойчивых результатов по причине улучшения отношения сигнал-помеха и возможности использования более протяжённых временных интервалов.
В работе [35] авторы для расчета когерентности предложили использовать функцию взаимной корреляции смежных сейсмических трасс. Затем было предложено использовать коэффициент подобия [42] и собственные значения корреляционной матрицы [41]. Все эти подходы затем были адаптированы к учету наклона отражающих границ [41]. Позднее эти алгоритмы были заменены методиками расчёта с использованием статистик высокого порядка вкупе с объединением смежных сейсмотрасс в т. н. "супертрассу», локальную структурную энтропию, а также сканированием наклонов отражённых волн.

Атрибут Ant-Tracking, запатентованный компанией Шлюмберже [50], особо ценится за технологию прослеживания разрывных нарушений, зон высокой плотности трещин и коридоров трещиноватости. Метод включает в себя нейронные сети с обучением для создания синергетического искусственного интеллекта на основе поведения колонии муравьев, что имитирует движение потока флюида по трещинам.

\section{Заключение}

Наиболее точными способом для обнаружения зон повышенной трещиноватости считаются скважинные измерения. Главным их недостатком является малый радиус исследования и невозможность использования на этапе прогнозирования коллектора по результатам полевых геофизических работ. Существующие методы выделения трещиноватости по сейсмическим методам являются достаточно точными, но косвенными. Это вызвано тем, что множество других явлений, например, 30ны выклиниваний, литологические замещения, да

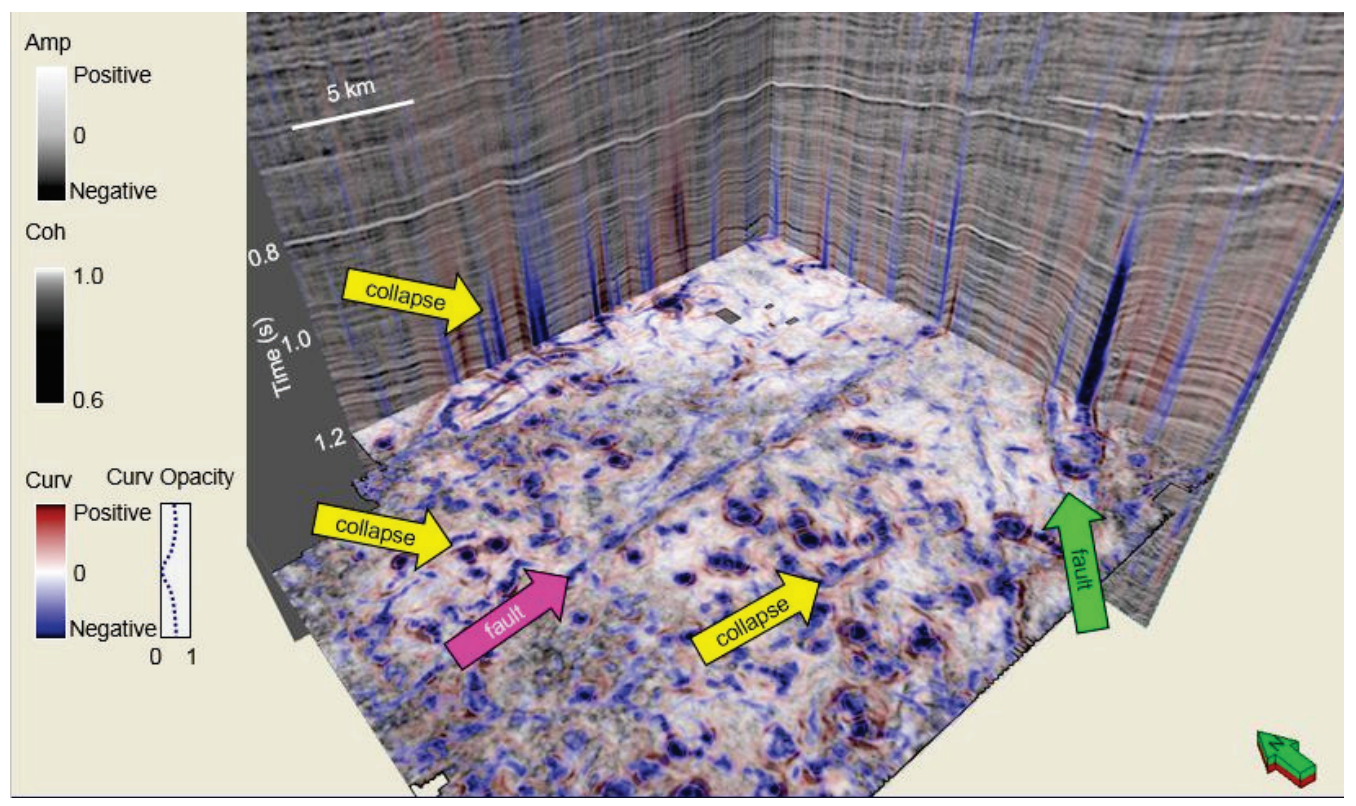

Pис. 4. Пример колплексирования трех сейслических атрибутов (наиболее положительная кривизна, $k 1$, и наибольшая отрицательная кривизна, $k 2$, и когерентность) на горизонте для выделения разлолов и трещиноватых зон [41, 42]

Fig. 4. Example of using slice of the most-positive and most-negative principal curvatures and coherency time slice at $t=1,2 \mathrm{~s}$ to isolate faults and fissured zones [41, 42] 
и просто артефакты, связанные с проведением полевых сейсморазведочных работ, дают сейсмический отклик, сравнимый с откликом от трещиноватости. Для наиболее полного понимания распространения трещиноватости в исследуемой породе недостаточно только сейсмических данных, необходимо комплексирование сейсморазведки с результатами других исследований, содержащих информацию о трещинах. Очевидно, что использование в прогностических целях одного (любого) сейсмического атрибута неизбежно приведёт к получению недостаточно достоверных результатов. Поэтому, на наш взгляд, наиболее перспективным направлением исследований в этой области является интеграция (комплексирование) нескольких атрибутов, как это показано на рис. 4. Очевидно, что при таком подходе повышаются достоверность и детальность оценки зон с интенсивно развитой трещиноватостью. По на-

\section{СПИСОК ЛИТЕРАТУРЫ}

1. Ван Голф-Рахт Т.Д. Основы нефтепромысловой геологии и раз работки трещиноватых коллекторов // пер. с англ. Н.А. Бардиной, П.К. Голованова, В.В. Власенко, В.В. Покровского // под ред. А.Г. Ковалева. - М.: Недра, 1986. - 607 с.

2. Молодовский В.А., Поздняков В.А., Матросов К.О. Картирование особенностей площадного распространения отложений ванаварской свиты с использованием структурного атрибута сейсмического волнового поля // Вестник Воронежского государственного университета. Серия: Геология. - 2017. - № 1. C. $150-152$.

3. Кузин А.М. 0 флюидной составляющей процесс образования зон трещиноватости и разрывных нарушений // Геология, геофизика и разработка нефтяных и газовых месторождений. 2014. - № 5. - C. 43-50.

4. Оловяный А.Г. Механика норных пород. - М.: РАН, 2012. $280 \mathrm{c.}$

5. Stearns D.W., Friedman. M. Reservoir in fractured rock. Stratigraphic Oil and Gas Fields-Classification, Exploration Methods, and Case Histories / Memoir 16, Society of Exploration Geophysicists. - 1972. - № 10. - P. 82-106.

6. Невский В.А. Трещинная тектоника рудных полей и месторождений. - М.: Недра, 1979. - 224 с.

7. Чернышов С.Н. Трещины горных пород. - М.: Наука, 1983. $240 \mathrm{c.}$

8. Михайлов А.Е. Структурная геология и геологическое картирование. - М.: Недра, 1984. - 464 с.

9. Михайлова С.В. Анализ сейсмических атрибутов - комплексный подход при концептуальном моделировании // Ргонефть. Профессионально о нефти. - 2018. - № 2. - С. 31-35.

10. Cook A.C., Johnson K.R. Early joint formation in sediments // Geol. Mag. - 1970. - V. 107. - № 4. - P. 361-368.

11. Lisle R.J. Detection of zones of abnormal strains in structures using Gaussian curvature analysis // AAPG Bulletin. -1994. № 78. - P. 1811-1819.

12. Ramstad L.R. Geological modelling of fractured hydrocarbon reservoirs // Report Univ. of Trondheim. - 1977. - № 77-4.

13. Ермолов В.А. Геология. Ч. І. Основы геологии. - М.: МГУ, 2008. $-598 \mathrm{C}$.

14. Seismic attributes application to evaluate the GORU clastics of Indus basin, Pakistan / M.N. Tayyab, S. Asim, M.M. Siddiqui, M. Naeem, S.H. Solange, F.K. Babar // Arabian Journal of Geosciences. - 2017. - V. 10. - № 7. - P. 158-175.

15. Pirson S. How to map fracture development from well logs // World Oil. - March 1967. - P. 106-114. шему мнению, целесообразно комплексирование как минимум двух способов оценки интенсивности развития трещин, например, анализ ГИС и анализ сейсмических атрибутов.

Таким образом, очевидна необходимость дальнейшего изучения информативности сейсмических атрибутов с целью поиска путей повышения эффективности методик выделения трещиноватости. Эффективность сейсмического атрибутного анализа сегодня не вызывает вопросов. При этом остаются слабо изученными вопросы выбора атрибутов, наиболее подходящих для изучения трещиноватости и методик их анализа.

Также слабо исследованы вопросы их комплексирования для решения конкретных задач, они попрежнему достаточно часто решаются на интуитивном уровне и требуют дальнейшего углублённого изучения.

16. Использование новых технологий и методов для повышения эффективности ГИС / О.Л. Сальникова, А.Д. Савич, А.В. Серкина, А.С. Чухлов / / Теория и практика разведочной и промысловой геофизики. Сборник научных трудов по материалам международной научной-практической конференции. Пермь: Пермский государственный национальный исследовательский университет, 2018. - С. 246-252.

17. Aguilera R. Analysis of naturally fractured reservoirs from conventional well logs // Journal of Petroleum Technology. - July 1976. - № 7. - V. 28. - P. 764-775.

18. Beck J., Schultz A., Fitzgerald D. Reservoir evaluation of fractured cretaceous carbonates in South Texas // $18^{\text {th }}$ Annual Logging Symposium. - Houston, Texas Society of Petrophysicists and Well Log Analysts, 5-8 June, 1977. - 25 p.

19. Aguilera R., Van Poolen K. How to evaluate naturally fractured reservoirs from various well logs // Oil and Gas Journal. - Jan 1979. - P. 56-57.

20. The Borehole Televiewer - a New Logging Concept for Fracture Location and Other Types of Borehole Inspection. SPE $2402 /$ J. Zemanek, R.L. Caldwell, E.E. Glenn Jr., S.V. Holcomb, L.J. Norton, A.J.D. Straus // Journal of Petroleum Technology. 1969 - V. 21 - № 6. - P. 762-774.

21. Morris R.L., Grine D.R., Arkfeld T.E. Using Compressional and Shear Acoustic Amplitudes for The Location of Fractures // Journal of Petroleum Technology. - June 1964. - V. 16. - № 6. P. 623-633.

22. Князев А.Р., Малиновский А.К., Некрасов А.Н. Выделение тонких проницаемых пластов и уточнение границ коллекторов по данным скважинного акустического сканера // Каротажник. - 2017. - № 10 (280). - С. 34-40.

23. Шерстобитов В.В., Щербак А.С., Попов А.А. Применение сканирующих методов каротажа для уточнения геологического строения горных пород // Каротажник. - 2017. - № 7 (277). C. $30-39$.

24. Возможности бокового сканирующего каротажа для оценок трещиноватости и әффекта вызванной поляризации пород / А.П. Потапов, Г.И. Головацкая, В.Н. Даниленко, В.В. Даниленко, Т.С. Мамлеев // Каротажник. - 2011. - № 5 (203). C. $53-62$.

25. Fracture detection in oil-based drilling mud using a combination of borehole image and sonic logs / J. Lai, G. Wang, Z. Fan, J. Chen, Z. Zhou, S. Wang, Z. Wang, C. Xiao // Marine and Petroleum Geology. - 2017. - V. 84. - P. 195-214.

26. Сребродольская М.А., Федорова А.Ю. Скважинные сканирующие устройства: сравнительный анализ и интерпретация ими- 
джей // Природные процессы в нефтегазовой отрасли. Сборник научных трудов Международной научно-практической конференции Студенческого отделения европейской ассоциации геоученых и инженеров. - Тюмень: Тюменский индустриальный университет: Библиотечно-издательский комплекс федерального государственного бюджетного образовательного учреждения высшего образования, 2017. C. $264-267$.

27. Suau I.J., Gartner J. Fracture detection from logs // The log analyst. - March-April 1980. - V. 21 (2). - P. 3-13.

28. Seismic detection of subtle faults and fractures / V. Aarre, D. Astratti, T.N. Dayyni, S.L. Mahmoud, A. Clark, M. Stellas, J. Stringer, B. Toelle, 0. Vejbaek, G. White // Oilfield Review. - 2012. V. 24. - № 2. - P. 28-43.

29. Grechka V. Applications of seismic anisotropy in the oil and gas industry. - Moscow: EAGE, 2014. - $171 \mathrm{p}$.

30. Grechka V., Mateeva A. Inversion of P-wave VSP data for local anisotropy: Theory and a case study // Geophysics. - 2007. V. 72. - № 4. - P. 69-79.

31. Crampin S. Evaluation of anisotropy by shear-wave splitting // Geophysics. - 1985. - № 50. - P. 142-152.

32. Crampin S. The New Geophysics: shear-wave splitting provides a window into the crack-critical rock mass 2003b // Leading Edge. 2003. - № 22. - P. 536-549.

33. Lynn H. B., Thomsen L.A. Shear wave exploration along the principal axis // $56^{\text {th }}$ Annual International Meeting, SEG. - Houston, TX (United States), 1986. - P. 473-476.

34. Relationship of P-Wave Seismic Attributes, Azimuthal Anisotropy, and Commercial Gas Pay in 3-D P-Wave Multiazimuth Data, Rulison Field, Piceance Basin, Colorado / H.B. Lynn, D. Campagna, K.M. Simon, W.E. Beckham // Geophysics. - July, August 1999. - № 4. - P. 1293-1311.

35. Bahorich M.S., Farmer S.L. 3-D seismic discontinuity for faults and stratigraphic features: The coherence cube $/ / 65^{\text {th }}$ Annual International Meeting. - Houston, TX (United States), 1995. P. 93-96.

36. Blumentritt C.H., Marfurt K.J., Sullivan E.C. Volume-based curvature computations illuminate fracture orientations-Early to mid-Paleozoic, Central Basin Platform, West Texas // Geophysics. - 2006. - V. 71. - № 5. - P. 159-166.

37. Gersztenkorn A., Marfurt K.J. Eigenstructure-based coherence computations as an aid to 3-D structural and stratigraphic mapping // Geophysics. - 1999. - V. 64. - № 5. - P. 1468-1479.

38. Кирилов А.С., Закревский К.Е. Практикум по сейсмической интерпретации в Petrel. - М.: Изд-во Маи-принт, 2014. - 288 с.

39. Коннов Д.А., Курмангалиев С.Б., Бражник А.Ю. Методика выявления разрывных нарушений на основании данных сейсморазведки при помощи различных методов атрибутивного анализа // Материалы VIII Международной научно-практической конференции. - Астрахань: Астраханский государственный технический университет, 2017. - С. 76-79.
40. Mai H.T. Coherence and volumetric curvatures and their spatial relationship to faults and folds, an example from Chicontepec basin, Mexico // 79 $9^{\text {th }}$ SEG Meeting: Expand. Abstr. - Houston, TX (United States), 2009. - P. 1063-1067.

41. Сейсмическая когерентность при флуктуациях временных задержек сигнала / Ю.К. Тяпкин, Я.В. Мендрий, А.Ю. Щеголихин, А.Н. Тяпкина // Геофизический журнал. - 2018. T. 40, - № 2. - C. 30-47.

42. Septian L.S., Maulana A.I. Geological model of reservoir based on seismic attributes and ant tracking case study - $\mathrm{f3}$ block, offshore Netherlands // $75^{\text {th }}$ European Association of Geoscientists and Engineers Conference and Exhibition 2013 Incorporating. - London, UK, 2013. - P. 6183-6185.

43. Мельник И.А. Вторичная каолинизация песчаных пластов как признак тектонических нарушений осадочного чехла // Геология, геофизика и разработка нефтяных и газовых месторождений. - 2014. - № 9. - С. 22-27.

44. Швецова М.Н. Прогноз коллекторских свойств на основе атрибутного анализа // Сборник научных трудов по материалам XI Международной научно-практической конференции студентов, аспирантов и молодых ученых. В 3-х т. - Пермь, 2018. - Пермь: Пермский государственный национальный исследовательский университет, 2018. - С. 325-329.

45. Митюхина И.Ю., Спасский Б.А., Заключнов И.С. Изучение межскважинного пространства на основе многомерного анализа атрибутов сейсмических записей // Геофизика. - 2017. № 5. - C. 44-49.

46. Волкова А.А. Комплексный анализ сейсмических и скважинных данных при изучении трещиноватых коллекторов на примере месторождения в фундаменте // Проблемы геологии и освоения недр: Труды XXI Международного симпозиума имени академика М.А. Усова студентов и молодых учёных, посвященного 130-летию со дня рождения профессора М.И. Кучина. - Томск, 2017. - С. 356-358.

47. Chopra S., Marfurt K.J. Integration of coherence and volumetric curvature images // The Leading Edge. - 2010. - V. 29. - № 9. P. 1092-1107.

48. Chopra S., Marfurt K.J. Volumetric curvature attributes for fault fracture characterization. / First Break. - 2007. - V. 25. № 7. - P. 35-46.

49. Roberts A. Curvature attributes and their application to 3D interpreted horizons // First Break. - 2001. - V. 19. - № 2. P. $85-100$.

50. Абетова С.А., Абетов А.Е. Интерпретация тектонических нарушений в объектах моделирования с использованием алгоритма Ant-tracking в программном обеспечении Petrel // Геология и охрана недр. - 2017. - № 4 (65). - С. 51-55.

Поступила 09.05.2019 г.

\section{Информация об авторах}

Орехов А.Н., кандидат геолого-минералогических наук, доцент отделения геологии Инженерной школы природных ресурсов Национального исследовательского Томского политехнического университета.

Амани Мангуа Марк М, аспирант отделения геологии Инженерной школы природных ресурсов Национального исследовательского Томского политехнического университета. 
UDC 550.832, 550.834.05

\title{
POSSIBILITIES OF GEOPHYSICAL METHODS FOR PREDICTING RESERVOIR FRACRURES
}

\section{Alexandr N. Orekhov',}

orekhovan@mail.tomsknet.ru

\author{
Amani Mangoua Marc M', \\ mangouam@yahoo.fr
National Research Tomsk Polytechnic University, 30, Lenin Avenue, Tomsk, 634050, Russia.

This article presents the results of an analysis of Russian and foreign publications, performed in order to characterize the current state of an issue of using geophysical methods to predict reservoir fracturing. The paper describes the peculiarities of fracture occurrence depending on its genesis. The authors have characterized tectonic and geological conditions of crack formation and the relation between cracks and fissures. The text also provides a geological model of cracking. The paper introduces the characteristic of methods which allows tstudying the fracturing both in a well (the methods of geophysical surveys of wells) and from the surface (according to the results of seismic exploration) and the features of the most demanded seismic attributes for solution of these problems. The description is given and the range of tasks to be solved is determined both for the most widespread variants of well logging and innovative methods offered by Schlumberger on the basis of well logging methods. A conclusion is made that well logging methods need to be integrated. The physical bases of seismic study methods of fracturing are given and the main attributes are described. Their capabilities and limitations are determined and as a result the range of issues demanding additional research is outlined.

The aim of the research is to identify the areas for further research in order to improve the efficiency of geophysical work in studying fractured reservoirs by creating a review of geophysical methods used to identify the areas for increasing fractures, further analysis of existing methods and determination of the best ways to solve these problems.

Results. The article analyzes geophysical methods for identification of fractured reservoirs (both well logging methods and seismic attributes). The circle of unsolved problems is defined. The direction for further research is outlined.

\section{Key words:}

Reservoir, fissured-cavernous type, seismic attributes, geophysical methods of well logging.

\section{REFERENCES}

1. Van Golff-Raht T.D. Osnovy neftepromyslovoy geologii i razrabotki treshchinovatykh kollektorov [Fundamentals of fractured reservoirs engineering]. Translated from English by N.A.. Bardina, P.K. Golovanov, V.V. Vlasenko, V.V. Pokrovsky. Ed. by A.G. Kovalev. Moscow, Nedra Publ., 1986. 607 p.

2. Molodovskiy V.A., Pozdnyakov V.A., Matrosov K.0. Mapping the features of areal distribution of Vanavara formation deposits using structure attribute of seismic wave field. Bulletin of the Voronezh State University. Series: Geology, 2017, no. 1, pp. 150-152. In Rus.

3. Kuzin A.M. Fluid component of formation of fracturing zones and discontinuous disturbances. Geology, geophysics and development of oil and gas fields, 2014, no. 5, pp. 43-50. In Rus.

4. Oliavin A.G. Mekhanika gornykh porod [Mechanics of rocks]. Moscow, RAS Publ., 2012. 280 p.

5. Stearns D.W., Friedman. M. Reservoir in fractured rock. Stratigraphic Oil and Gas Fields-Classification, Exploration Methods, and Case Histories. Memoir 16, Society of Exploration Geophysicists, 1972, no. 10, pp. 82-106.

6. Nevsky V.A. Treshchinnaya tektonika rudnykh poley i mestorozhdeniy [Fractured tectonics of fields and deposits]. Moscow, Nedra Publ., 1979. 224 p.

7. Chernyshov S.N. Treshchiny gornykh porod [Cracks of rocks]. Moscow, Nauka Publ., 1983. 240 p.

8. Mikhailov A.E. Strukturnaya geologiya i geologicheskoe kartirovanie [Structural geology and geological mapping]. Moscow, Nedra Publ., 1984. 464 p.

9. Mikhailova S.V. Conceptual model, attribute analysis, petrophysical model, seismofacial model. Proneft. Professionally about oil, 2018, no. 2, pp. 31-35. In Rus.

10. Cook A.C., Johnson K.R. Early joint formation in sediments. Geol. Mag., 1970, vol. 107, no. 4, pp. 361-368.

11. Lisle R.J. Detection of zones of abnormal strains in structures using Gaussian curvature analysis. AAPG Bulletin, 1994, no. 78, pp. 1811-1819.
12. Ramstad L.R. Geological modelling of fractured hydrocarbon reservoirs. Report Univ. of Trondheim, 1977. No. 77-4.

13. Ermolov V.A. Geologiya. Ch. I. Osnovy geologii [The fundamentals of geology. P. I]. Moscow, MSU Publ., 2004. 598 p.

14. Tayyab M.N., Asim S., Siddiqui M.M., Naeem M., Solange S.H., Babar F.K. Seismic attributes' application to evaluate the goru clastics of Indus basin, Pakistan. Arabian Journal of Geosciences, 2017, vol. 10, no. 7, pp. 158-175.

15. Pirson S. How to map fracture development from well logs. World Oil, March 1967, pp. 106-114.

16. Salnikova 0.L., Savich A.D., Serkina A.V., Chukhlov A.S. Ispolzovanie novykh tekhnologiy i metodov dlya povysheniya effektivnosti GIS [Using new technologies and methods to improve the effectiveness of Well logging]. Teoriya i praktika razvedochnoy $i$ promyslovoy geofiziki. Sbornik nauchnykh trudov po materialam mezhdunarodnoy nauchno-prakticheskoy konferentsii [Theory and practice of exploration and field geophysics. Collection of scientific papers on the materials of the international scientificpractical conference]. Perm, Perm State National Research University, 2018, pp. 246-252.

17. Aguilera R. Analysis of naturally fractured reservoirs from conventional well logs. Journal of Petroleum Technology, July 1976, vol. 28, no. 7, pp. 764-775.

18. Beck J., Schultz A., Fitzgerald D. Reservoir evaluation of fractured cretaceous carbonates in South Texas. $18^{\text {th }}$ Annual Logging Symposium. Houston, Texas Society of Petrophysicists and Well Log Analysts, 5-8 June, 1977. 25 p.

19. Aguilera R., Van Poolen K.H. How to evaluate naturally fractured reservoirs from various well logs. Oil and Gas Journal, Jan 1979, pp. 56-57.

20. Zemanek J., Caldwell R.L., Glenn E.E. Jr., Holcomb S.V., Norton L.J., Straus A.J.D. The Borehole Televiewer - a New Logging Concept for Fracture Location and Other Types of Borehole Inspection. SPE 2402. Journal of Petroleum Technology, 1969, vol. 21, no. 6, pp. 762-774. 
21. Morris R.L., Grine D.R., Arkfeld T.E. Using Compressional and Shear Acoustic Amplitudes for The Location of Fractures. Journal of Petroleum Technology, June 1964, vol. 16, no. 6, pp. 623-633.

22. Knyazev A.R., Malinovsky A.K., Nekrasov A.N. Detecting thin permeable formations and refining reservoir boundaries from the downhole sonic scanner information. Logger, 2017, no. 10 (280), pp. 34-40. In Rus.

23. Sherstobitov V.V., Shcherbak A.S., Popov A.A. Applying scanning logs to refine the geological structure of the rocks. Logger, 2017, no. 7 (277), pp. 30-39. In Rus.

24. Potapov A.P., Golovatskaya G.I., Danilenko V.N., Danilenko V.V., Mamleev T.S. Capabilities of scanning lateral logging for evaluation of rock fracturing and induced polarization effect. Logger, 2011, no. 5 (203), pp. 53-62. In Rus.

25. Lai J., Wang G., Fan Z., Chen J., Zhou Z., Wang S., Wang Z., Xiao C. Fracture detection in oil-based drilling mud using a combination of borehole image and sonic logs. Marine and Petroleum Geology, 2017, vol. 84, pp. 195-214.

26. Srebrodolskaya M.A, Fedorova A.Y. Skvazhinnye skaniruyushchie ustroystva: sravnitelny analiz i interpretatsiya imidzhey [Wells Scanning Devices: Comparative Analysis and Image Interpretation]. Prirodnye processy v neftegazovoy otrasli. Sbornik nauchnykh trudov Mezhdunarodnoy nauchno-prakticheskoy konferentsii Studencheskogo otdeleniya europeyskoy assotsiacii geouchenykh $i$ inzhenerou [Natural Processes in the Oil and Gas Industry. Collection of scientific papers of the International Scientific and Practical Conference of the Student Branch of the European Association of Geoscientists and Engineers]. Tyumen, Tyumen Industrial University Publ., 2017. pp. 264-267.

27. Suau I.J., Gartner J. Fracture detection from logs. The log analyst, March-April 1980, vol. 21 (2), pp. 3-13.

28. Aarre V., Astratti D., Dayyni T.N., Mahmoud S.L., Clark A., Stellas M., Stringer J., Toelle B., Vejbaek 0, White G. Seismic detection of subtle faults and fractures. Oilfield Review, 2012, vol. 24 , no. 2 , pp. 28-43.

29. Grechka V. Applications of seismic anisotropy in the oil and gas industry. Moscow, EAGE, 2014. $171 \mathrm{p}$.

30. Grechka V., Mateeva A. Inversion of P-wave VSP data for local anisotropy: Theory and a case study. Geophysics, 2007, vol. 72, no. 4, pp. 69-79.

31. Crampin S. Evaluation of anisotropy by shear-wave splitting. Geophysics, 1985, no. 50, pp. 142-152.

32. Crampin S. The New Geophysics: shear-wave splitting provides a window into the crack-critical rock mass 2003b. Leading Edge, 2003, no. 22 , pp. 536-549.

33. Lynn H.B., Thomsen L.A. Shear wave exploration along the principal axis. $56^{\text {th }}$ Annual International Meeting, SEG. Houston, TX (United States), 1986. pp. 473-476.

34. Lynn H.B., Campagna D., Simon K.M., Beckham W.E. Relationship of P-Wave Seismic Attributes, Azimuthal Anisotropy, and Commercial Gas Pay in 3-D P-Wave Multiazimuth Data, Rulison Field, Piceance Basin, Colorado. Geophysics, July, August 1999, no. 4, pp. 1293-1311.

35. Bahorich M.S., Farmer S.L. 3-D seismic discontinuity for faults and stratigraphic features: The coherence cube. $65^{\text {th }}$ Annual International Meeting, Houston, TX (United States), 1995. pp. 93-96.

36. Blumentritt C.H., Marfurt K.J., Sullivan E. Volume-based curvature computations illuminate fracture orientations-Early to midPaleozoic, Central Basin Platform, West Texas. Geophysics, 2006, vol. 71, no. 5, pp. 159-166.

37. Gersztenkorn A., Marfurt K. J. Eigenstructure-based coherence computations as an aid to 3-D structural and stratigraphic mapping. Geophysics, 1999, vol. 64, no. 5, pp. 1468-1479.
38. Kirilov A.S., Zakrevsky K.E. Praktikum po seysmicheskoy interpretatsii v Petrel [Workshop on seismic interpretation in Petrel]. Moscow, Mai-print Publ., 2014. 288 p.

39. Konnov D.A., Kurmangaliyev S.B., Brazhnik A.Yu. Metodika vyyavleniya razryvnykh narusheniy na osnovanii dannykh seysmorazvedki pri pomoshchi razlichnykh metodov atributivnogo analiza [Methods of detecting faults based on seismic data using various methods of attributive analysis]. Materialy VIII Mezhdunarodnoy nauchno-prakticheskoy konferentsii [Materials of the VIII International Scientific and Practical Conference]. Astrakhan, Astrakhan State Technical University Press, 2017. pp. 76-79.

40. Mai H.T. Coherence and volumetric curvatures and their spatial relationship to faults and folds, an example from Chicontepec basin, Mexico. $79^{\text {th }}$ SEG Meeting: Expand. Abstr. Houston, TX (United States), 2009. pp. 1063-1067.

41. Tyapkin Yu.K., Mendriy Ya.V., Schegolikhin A.Yu., Tyapkina A.N. Seismic coherence in the presence of signal time-delay fluctuations. Geophysical journal, 2018, vol. 40, no. 2, pp. 30-47. In Rus.

42. Septian L.S., Maulana A.I. Geological model of reservoir based on seismic attributes and ant tracking case study - $\mathrm{f} 3$ block, offshore Netherlands. $75^{\text {th }}$ European Association of Geoscientists and Engineers Conference and Exhibition 2013 Incorporating. London, UK, 2013. pp. 6183-6185.

43. Melnik I.A. Secondary kaolinization of sand layers as a sign of tectonic disturbance of the sedimentary cover. Geology, geophysics and development of oil and gas fields, 2014, no. 9, pp. 22-27. In Rus.

44. Shvetsova M.N. Prognoz kollektorskikh svoystv na osnove atributnogo analiza [Prediction of reservoir properties based on attribute analysis]. Sbornik nauchnykh trudov po materialam XI Mezhdunarodnoy nauchno-prakticheskoy konferentsii studentov, aspirantov $i$ molodykh uchenykh [Proc. of the XI International scientific conference of students, postgraduates and young scientists]. Perm, Perm State National Research University Press, 2018. pp. 325-329.

45. Mityukhina I.Yu., Spassky B.A., Kronovna I.S. Study of the interwell space based on multidimensional analysis of the attributes of seismic records. Geophysics, 2017, no. 5, pp. 44-49.

46. Volkova A.A. Kompleksny analiz seysmicheskikh i skvazhinnykh dannkyh pri izuchenii treshchinovatykh kollektorov na primere mestorozhdeniya $\mathrm{v}$ fundamente [Analysis of seismic and well data when studying fractured reservoirs using the example of a field in the basement of western Siberia]. Problemy geologii $i$ osvoeniya nedr. Trudy XXI Mezhdunarodnogo simpoziuma imeni akademika M.A.Usova studentov i molodykh uchenykh, posvyashchennogo 130-letiyu so dnya rozhdeniya professora M.I. Kuchina [Problems of Geology and Subsoil Development. Proc. of the XXI International Symposium of academician M.A. Usov of students and young scientists dedicated to the $130^{\text {th }}$ anniversary of the birth of professor M.I. Kuchin]. Tomsk, 2017. pp. 356-358.

47. Chopra S., Marfurt K.J. Integration of coherence and volumetric curvature images. The Leading Edge, 2010, vol. 29, no. 9, pp. 1092-1107.

48. Chopra S., Marfurt K.J. Volumetric curvature attributes for fault fracture characterization. Chopra. First Break, 2007, vol. 25, no. 7 , pp. $35-46$.

49. Roberts A. Curvature attributes and their application to 3D interpreted horizons. First Break, 2001, vol. 19, no. 2, pp. 85-100.

50. Abetova S.A., Abetov A.E. Interpretation of tectonic disturbances in modeling objects using the ant-tracking algorithm in Petrel software. Geology and protection of mineral resources, 2017, no. 4 (65), pp. 51-55. In Rus.

Received: 9 May 2019.

\section{Information about the authors}

Alexander N. Orekhov, Cand. Sc., associate professor, National Research Tomsk Polytechnic University.

Amani Mangoua Marc M, postgraduate student, National Research Tomsk Polytechnic University. 